\title{
Functional and quality-of-life outcomes in geriatric patients with type-II dens fracture.
}

\author{
Alexander R Vaccaro \\ Rothman Institute, Thomas Jefferson University \\ Christopher K Kepler \\ Rothman Institute, Thomas Jefferson University \\ Branko Kopjar \\ Rothman Institute, Thomas Jefferson University \\ Jens Chapman \\ Rothman Institute, Thomas Jefferson University \\ Follow this and additional works at: https://jdc.jefferson.edu/rothman_institute \\ fl ristopher Shaffrey

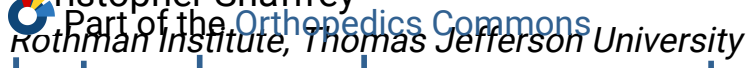 \\ Let us know how access to this document benefits you
}

\section{See next page for additional authors}

Recommended Citation

Vaccaro, Alexander R; Kepler, Christopher K; Kopjar, Branko; Chapman, Jens; Shaffrey, Christopher; Arnold, Paul; Gokaslan, Ziya; Brodke, Darrel; France, John; Dekutoski, Mark; Sasso, Rick; Yoon, S Tim; Bono, Christopher; Harrop, James; and Fehlings, Michael G, "Functional and quality-of-life outcomes in geriatric patients with type-II dens fracture." (2013). Rothman Institute Faculty Papers. Paper 25.

https://jdc.jefferson.edu/rothman_institute/25

This Article is brought to you for free and open access by the Jefferson Digital Commons. The Jefferson Digital Commons is a service of Thomas Jefferson University's Center for Teaching and Learning (CTL). The Commons is a showcase for Jefferson books and journals, peer-reviewed scholarly publications, unique historical collections from the University archives, and teaching tools. The Jefferson Digital Commons allows researchers and interested readers anywhere in the world to learn about and keep up to date with Jefferson scholarship. This article has been accepted for inclusion in Rothman Institute Faculty Papers by an authorized administrator of the Jefferson Digital Commons. For more information, please contact: JeffersonDigitalCommons@jefferson.edu. 


\section{Authors}

Alexander R Vaccaro, Christopher K Kepler, Branko Kopjar, Jens Chapman, Christopher Shaffrey, Paul Arnold, Ziya Gokaslan, Darrel Brodke, John France, Mark Dekutoski, Rick Sasso, S Tim Yoon, Christopher Bono, James Harrop, and Michael G Fehlings 


\title{
Functional and Quality-of-Life Outcomes in Geriatric Patients with Type-II Dens Fracture
}

\author{
Alexander R. Vaccaro, MD, PhD, Christopher K. Kepler, MD, MBA, Branko Kopjar, MD, PhD, MS, Jens Chapman, MD, \\ Christopher Shaffrey, MD, Paul Arnold, MD, Ziya Gokaslan, MD, Darrel Brodke, MD, John France, MD, \\ Mark Dekutoski, MD, Rick Sasso, MD, S. Tim Yoon, MD, Christopher Bono, MD, \\ James Harrop, MD, and Michael G. Fehlings, MD, PhD
}

\begin{abstract}
Background: Dens fractures are relatively common in the elderly. The treatment of Type-Il dens fractures remains controversial. The aim of this multicenter prospective cohort study was to compare outcomes (assessed with use of validated clinical measures) and complications of nonsurgical and surgical treatment of Type-ll dens fractures in patients sixty-five years of age or older.
\end{abstract}

\begin{abstract}
Methods: One hundred and fifty-nine patients with a Type-II dens fracture were enrolled in a multicenter prospective study. Subjects were treated either surgically $(n=101)$ or nonsurgically $(n=58)$ as determined by the treatment preferences of the treating physicians and the patients. The subjects were followed at six and twelve months with validated outcome measures, including the Neck Disability Index (NDI) and Short Form-36v2 (SF-36v2). Treatment complications were prospectively recorded. Statistical analysis was performed to compare outcome measures before and after adjustment for confounding variables.
\end{abstract}

Results: The two groups were similar with regard to baseline characteristics. The most common surgical treatment was posterior C1-C2 arthrodesis (eighty of 101, or $79 \%$ ) while the most common nonsurgical treatment was immobilization with use of a hard collar (forty-seven of fifty-eight, or $81 \%$ ). The overall mortality rate was $18 \%$ over the twelve-month followup period. At twelve months, the NDI had increased (worsened) by 14.7 points in the nonsurgical cohort $(p<0.0001)$ compared with a nonsignificant increase (worsening) of 5.7 points in the surgical group $(p=0.0555)$. The surgical group had significantly better outcomes as measured by the NDI and SF-36v2 Bodily Pain dimension compared with the nonsurgical group, and these differences persisted after adjustment. There was no difference in the overall rate of complications, but the surgical group had a significantly lower rate of nonunion ( $5 \%$ versus $21 \%$ in the nonsurgical group; $p=$ 0.0033 ). Mortality was higher in the nonsurgical group compared with the surgical group (annual mortality rates of $26 \%$ and $14 \%$, respectively; $p=0.059$ ).

Conclusions: We demonstrated a significant benefit with surgical treatment of dens fractures as measured by the NDI, a disease-specific functional outcome measure. As a result of the nonrandomized nature of the study, the results are vulnerable to the effects of possible residual confounding. We recommend that elderly patients with a Type-II dens fracture who are healthy enough for general anesthesia be considered for surgical stabilization to improve functional outcome as well as the union and fusion rates.

Level of Evidence: Therapeutic Level II. See Instructions for Authors for a complete description of levels of evidence.

$\mathrm{T}$ 1 ype-II dens fracture-i.e., a fracture through the base of the dens just above the $\mathrm{C} 2$ vertebral body-is the most common cervical spine fracture in patients sixty-five years of age or older, and these injuries represent the majority of cervical spine fractures in patients over eighty years of age ${ }^{1}$. In contrast to similar injuries in younger patients, dens fractures in the elderly are typically sustained by low-energy mechanisms $\mathrm{s}^{2-5}$. Like younger patients, elderly individuals with a dens fracture

\footnotetext{
Disclosure: One or more of the authors received payments or services, either directly or indirectly (i.e., via his or her institution), from a third party in support of an aspect of this work. In addition, one or more of the authors, or his or her institution, has had a financial relationship, in the thirty-six months prior to submission of this work, with an entity in the biomedical arena that could be perceived to influence or have the potential to influence what is written in this work. No author has had any other relationships, or has engaged in any other activities, that could be perceived to influence or have the potential to influence what is written in this work. The complete Disclosures of Potential Conflicts of Interest submitted by authors are always provided with the online version of the article.
} 
most commonly present without associated spinal cord injury ${ }^{5-7}$, a finding that has been attributed to the relative capaciousness of the spinal canal at this level. ${ }^{8}$. Optimal treatment of geriatric patients with a Type-II dens fracture would permit patients to return to their prior level of function as rapidly as possible while avoiding the morbidity and mortality associated with prolonged inactivity and hospitalization.

The studies of Type-II dens fractures in the elderly that have been published in the literature are relatively small, uncontrolled case series that often preclude direct comparison of treatment modalities to determine the optimal strategy for this injury". The existing literature has, however, established that this population is at a high risk of complications regardless of whether they are treated with a cervical orthosis ${ }^{10,11}$, a halo vest $^{4,7,11}$, or surgical intervention ${ }^{6,12}$. Few investigators have evaluated outcomes using validated, patient-derived outcome measures such as the Short Form-36 (SF-36) or Neck Disability Index (NDI). Because of the lack of controlled studies and the wide variation in clinical practice among experienced spine surgeons, the treatment of Type-II dens fractures in the elderly is characterized by clinical equipoise between nonsurgical and surgical approaches. Evidence-based treatment algorithms have the potential to optimize outcomes in elderly patients with a Type-II dens fracture.

The aim of this multicenter prospective cohort study was to compare, with the use of validated clinical outcome measures, outcomes and complications of nonsurgical and different types of surgical treatment of Type-II dens fractures in patients sixtyfive years of age or older.

\section{Materials and Methods Subjects}

f 225 patients with a radiographically confirmed Type-II dens fracture, sites in the United States and one site in Canada between January 2006 and May 2009. Sites were selected among the members of SpineNET, the clinical research network of AOSpine North America. To be enrolled in the study, patients had to be sixty-five years of age or older, have had a Type-II dens fracture for not longer than ninety days, have had no previous fracture treatment, and no substantial cognitive impairment. Sixty-six of the 225 patients who had been determined to have a Type-II dens fracture on initial screening for the study were excluded because they did not meet one or more inclusion/exclusion criteria or could not provide information about primary outcome variables. Subjects were managed nonsurgically or surgically on the basis of treatment decisions reached by the treating physicians and patients. No protocol-mandated procedure was used to direct the choice of nonsurgical or surgical treatment. Postsurgical rehabilitation was dictated by the treatment protocols at the participating institutions and was not mandated by the investigational protocol.

\section{Outcomes Data}

Subjects were followed prospectively with validated outcome measures-the Neck Disability Index (NDI) ${ }^{13,14}$ and the Short Form-36v2 (SF-36v2) ${ }^{15,16}$ - as well as for treatment complications at six and twelve months after the initial treatment. The baseline NDI and SF-36v2 scores were based on the subjects' evaluation of their status prior to sustaining the injury. The NDI is a selfreported questionnaire that evaluates functional outcomes related to neck conditions; the scores range from 0 (best) to 100 (worst). The SF-36v2 is a widely used measure of patient-reported generic health status that describes health status across eight global dimensions of health: Physical Functioning,
Role Limitation-Physical, Bodily Pain, General Health, Emotional Well-Being, Role Limitation-Emotional, Social Functioning, and Energy/Fatigue. The eight global dimensions can also be summarized with two composite scores: the SF36v2 Physical Component Summary (PCS) and Mental Component Summary (MCS) scores. The composite scores were calculated with use of the 1998 U.S. norms and the orthogonal approach to transformation.

Complications were prospectively followed with use of a predetermined list of nineteen anticipated complications associated with the treatment of dens fracture, and complications not on the list were also recorded on the standardized forms with use of write-in sections for additional complications. The same list of complications and the same procedure for prospective collection of adverse event data were applied at each institution. Adverse-events data were adjudicated by an adverse-event committee that consisted of a group of physicians participating in the study who were blinded to the patients and participating institutions. Adverse events were categorized as treatment complications and treatment-unrelated events. To ensure accuracy of mortality information, we crosschecked mortality against the information available at the ancestry.com database.

The study was externally monitored to ensure that the data were accurate, reliable, and complete. The SF-36v2 and NDI forms were completed by the subjects themselves. The data from the subjects' forms and other primary sources of data were transcribed on an ongoing basis with use of a U.S. FDA (Food and Drug Administration) Good Clinical Practice-compliant web-based electronic data-capture system and were processed at a central Data Management Center.

\section{Analytical Methods}

The study end points were the absolute changes between the preinjury and six and twelve-month post-treatment scores for the NDI, the eight SF-36v2 health dimensions, and the two SF-36v2 composite summary (PCS and MCS) scores. A prestudy sample size estimate demonstrated that 150 subjects were needed for an $80 \%$ power to detect a difference of 7.5 points in the NDI (a primary study end point) between the surgical and nonsurgical groups, assuming a 70\%:30\% distribution of surgical versus nonsurgical cases. Missing follow-up scores for subjects who failed to attend their follow-up visit at twelve months were imputed with use of the last value carried forward approach if a six-month score was available. The last value carried forward approach was used for $19.0 \%$ of the subjects in the nonsurgical arm and $8.9 \%$ of those in the surgical arm. All analyses were performed with use of intention-to-treat principles. Patients who later crossed over to the other treatment group (from nonsurgical to surgical) were kept in their original treatment group for the purpose of comparing group outcomes.

The main analyses of differences in preoperative and operative characteristics between the surgical and nonsurgical management groups were performed by using a Student $t$ test for continuous variables and a chi-square test for categorical variables. Testing of the significance of changes in outcome variables between the baseline data and the six and twelve-month data and of differences in changes between the nonsurgical and surgical arms was performed with repeated-measures analysis of variance (ANOVA). The analysis included factors denoted as ARM (nonsurgical or surgical), TIME (baseline, six months, and twelve months), and TIME*ARM. The factor ARM was used to analyze global differences between the nonsurgical and surgical groups and represents the influence of the treatment arm on the results. The factor TIME was used to analyze changes that occurred from baseline to six and twelve months to describe changes in results based on time since treatment. The interaction $\mathrm{TIME}^{\star} \mathrm{ARM}$ tests the significance of changes between the two groups once overall differences and general trend have been accounted for. From the perspective of the study objective, the most relevant parameter was the TIME*ARM interaction. Significant TIME*ARM interactions would indicate differences in outcomes between the groups. The actual testing was performed with use of SAS PROC GLM (SAS 9.2; SAS, Cary, North Carolina). To adjust for potential confounders, we used the following approach. The selection of baseline characteristics that might confound results and therefore required adjustment was performed in two steps, separately for each of eleven outcomes. First, we screened for potential adjustment variables by calculating the Pearson correlation coefficient between each candidate variable and the target change in 
TABLE I Patient Outcomes at Baseline and Six and Twelve Months Post-Treatment

\begin{tabular}{|c|c|c|c|c|c|c|c|c|c|}
\hline & \multicolumn{3}{|c|}{ Nonsurgical* } & \multicolumn{3}{|c|}{ Surgical* } & \multicolumn{3}{|c|}{ P Value } \\
\hline & Baseline & 6 Months & 12 Months & Baseline & 6 Months & 12 Months & TIME & ARM & TIME*ARM \\
\hline NDI & $18.27(2.82)$ & 34.19 (3.33) & 32.98 (3.43) & $21.67(2.11)$ & $25.61(2.49)$ & $27.26(2.57)$ & $<0.0001$ & 0.3072 & 0.0022 \\
\hline \multicolumn{10}{|l|}{ SF-36v2 } \\
\hline Physical Functioning & $39.40(2.18)$ & $36.50(2.12)$ & $36.94(2.31)$ & 38.69 (1.64) & $35.10(1.60)$ & $33.90(1.74)$ & 0.0068 & 0.4676 & 0.6312 \\
\hline Role Limitation-Physical & 41.56 (1.98) & $35.54(2.00)$ & $37.31(2.21)$ & 41.63 (1.49) & 37.45 (1.51) & $36.92(1.67)$ & 0.0011 & 0.7943 & 0.6426 \\
\hline Bodily Pain & $51.59(1.63)$ & $42.40(1.80)$ & 44.59 (1.85) & $46.17(1.22)$ & 48.49 (1.35) & 47.57 (1.39) & 0.0173 & 0.4787 & $<0.0001$ \\
\hline General Health & $49.31(1.76)$ & $45.58(1.77)$ & $45.90(1.76)$ & $47.68(1.31)$ & $46.29(1.31)$ & $46.20(1.31)$ & 0.0084 & 0.9150 & 0.4015 \\
\hline Emotional Well-Being & $52.14(1.77)$ & $47.10(1.93)$ & $48.41(1.94)$ & $49.58(1.32)$ & $49.71(1.45)$ & $48.69(1.45)$ & 0.0491 & 0.9555 & 0.0699 \\
\hline Role Limitation-Emotional & $46.84(2.00)$ & $38.23(2.46)$ & $39.28(2.64)$ & $47.24(1.51)$ & $40.96(1.86)$ & $41.47(2.00)$ & $<0.0001$ & 0.4618 & 0.7052 \\
\hline Social Functioning & $47.12(1.92)$ & $40.19(2.21)$ & $42.55(2.16)$ & 45.77 (1.45) & $44.26(1.67)$ & $44.68(1.63)$ & 0.0145 & 0.4418 & 0.1505 \\
\hline Energy/Fatigue & $52.51(1.84)$ & 44.50 (1.91) & $45.85(1.97)$ & $51.14(1.38)$ & $47.25(1.43)$ & $47.20(1.47)$ & $<0.0001$ & 0.6570 & 0.1394 \\
\hline $\begin{array}{l}\text { Physical Component } \\
\text { Summary score }\end{array}$ & 43.10 (1.69) & $38.66(1.73)$ & $39.93(1.84)$ & $41.00(1.28)$ & 39.49 (1.31) & $38.59(1.40)$ & 0.0117 & 0.6392 & 0.3242 \\
\hline $\begin{array}{l}\text { Mental Component } \\
\text { Summary score }\end{array}$ & $53.11(1.76)$ & $45.44(2.13)$ & $46.65(2.17)$ & $51.78(1.37)$ & 48.59 (1.65) & $48.76(1.69)$ & $<0.0001$ & 0.3362 & 0.1448 \\
\hline
\end{tabular}

*The numbers are mean values (standard error). NDI = Neck Disability Index, and SF = Short Form.

the outcomes score. Variables that were included as candidate predictors were demographic factors, comorbidities, presence of associated injuries, and Injury Severity Score (ISS). Second, candidate predictors with a $p$ value of $\leq 0.2$ were carried into a stepwise forward elimination multiple regression model with a threshold probability to stay in the model of $\mathrm{p} \leq 0.1$. Variables that remained in the multiple stepwise regression models were used as adjustment variables in the repeated-measures ANOVA models. As in the unadjusted analyses, the factors analyzed in the adjusted analyses were labeled ARM (nonsurgical and surgical), TIME (baseline, six months, and twelve months), and TIME*ARM interaction.

This study was approved by the institutional review boards at all participating sites and the institutional review board overseeing the central data management center. This study is registered with ClinicalTrials.gov (number NCT00266929).

\section{Source of Funding}

This study was funded by AOSpine North America. The funding source was not involved in the study design, data collection, data analysis, data interpretation, or writing of the report, nor was it involved in the decision to submit the paper for publication.

\section{Results}

f the 159 enrolled subjects, 101 were treated surgically and fifty-eight, with a cervical orthosis or halo immobilization. The majority of patients in both groups were treated within one week after injury. There were no differences in the time between the injury and initiation of treatment between groups ( $\mathrm{p}=$ $0.9969)$. Twenty-nine subjects $(18 \% ; 95 \%$ confidence interval [CI], $12.2 \%$ to $26.2 \%$ ) died before reaching the twelve-month follow-up point; fifteen were from the nonsurgical group (annual mortality rate of $26 \% ; 95 \% \mathrm{CI}, 14.5 \%$ to $42.7 \%$ ), and fourteen were from the surgical treatment group (annual mortality rate of $14 \%$; $95 \% \mathrm{CI}, 7.8 \%$ to $23.3 \%$ ) ( $\mathrm{p}=0.059)$. Three subjects withdrew from the study prior to twelve months. Of the

TABLE II Changes in Outcome Parameters Adjusted for Baseline Covariates

\begin{tabular}{|c|c|c|c|c|c|c|c|c|c|}
\hline & \multicolumn{3}{|c|}{ Nonsurgical* } & \multicolumn{3}{|c|}{ Surgical* } & \multicolumn{3}{|c|}{ P Value } \\
\hline & Baseline & 6 Months & 12 Months & Baseline & 6 Months & 12 Months & TIME & ARM & TIME*ARM \\
\hline NDI & $17.77(2.83)$ & $32.88(3.22)$ & $31.64(3.34)$ & $21.95(2.11)$ & $26.34(2.41)$ & $28.00(2.49)$ & $<0.0001$ & 0.5652 & 0.0071 \\
\hline \multicolumn{10}{|l|}{ SF-36v2 } \\
\hline Physical Functioning & 39.45 (2.19) & $36.47(2.13)$ & $36.83(2.30)$ & 38.66 (1.65) & $35.12(1.61)$ & $33.97(1.74)$ & 0.0006 & 0.4831 & 0.6881 \\
\hline Role Limitation-Physical & $40.99(2.12)$ & $37.12(2.05)$ & $39.15(2.28)$ & $41.96(1.56)$ & 36.55 (1.51) & $35.87(1.68)$ & 0.0047 & 0.6643 & 0.3380 \\
\hline Bodily Pain & $51.31(1.72)$ & $43.17(1.88)$ & $45.67(1.92)$ & $46.33(1.26)$ & $48.06(1.37)$ & $47.00(1.40)$ & 0.0057 & 0.8314 & 0.0014 \\
\hline General Health & 48.09 (1.85) & $46.04(1.95)$ & $47.09(1.92)$ & $48.36(1.32)$ & $46.04(1.40)$ & $45.54(1.38)$ & 0.0178 & 0.8456 & 0.5683 \\
\hline Emotional Well-Being & $52.01(1.80)$ & $47.14(1.98)$ & $48.86(1.95)$ & 49.65 (1.34) & $49.68(1.47)$ & $48.43(1.45)$ & 0.1191 & 0.9677 & 0.0863 \\
\hline Role Limitation-Emotional & $46.01(2.16)$ & $40.29(2.55)$ & $41.57(2.58)$ & $47.71(1.60)$ & $39.78(1.88)$ & $40.16(1.90)$ & 0.0132 & 0.9771 & 0.5944 \\
\hline Social Functioning & $46.28(2.06)$ & $41.38(2.35)$ & $44.04(2.31)$ & $46.25(1.51)$ & $43.59(1.72)$ & $43.84(1.69)$ & 0.0730 & 0.7790 & 0.6227 \\
\hline Energy/Fatigue & $52.37(1.92)$ & $45.62(1.97)$ & $46.67(2.06)$ & $51.22(1.41)$ & $46.62(1.45)$ & $46.85(1.51)$ & $<0.0001$ & 0.9711 & 0.5877 \\
\hline $\begin{array}{l}\text { Physical Component } \\
\text { Summary score }\end{array}$ & $42.90(1.82)$ & $39.66(1.76)$ & $41.32(1.88)$ & $41.11(1.35)$ & $38.92(1.30)$ & $37.78(1.39)$ & 0.0057 & 0.3987 & 0.4253 \\
\hline $\begin{array}{l}\text { Mental Component } \\
\text { Summary score }\end{array}$ & $52.16(1.91)$ & $46.06(2.23)$ & $46.44(2.27)$ & $52.35(1.42)$ & $48.15(1.66)$ & 48.85 (1.69) & 0.0239 & 0.4978 & 0.6701 \\
\hline
\end{tabular}


TABLE III Treatment Complications by Treatment

\begin{tabular}{|c|c|c|c|}
\hline Treatment Complication & Nonsurgical $(N=58)$ & Surgical $(N=101)$ & $\mathrm{P}$ Value \\
\hline Acute airway compromise* & $1(2 \%)$ & $4(4 \%)$ & Not significant \\
\hline Anuria & $1(2 \%)$ & $0(0 \%)$ & Not significant \\
\hline Arrhythmia & $0(0 \%)$ & $2(2 \%)$ & Not significant \\
\hline Bradycardia & $1(2 \%)$ & $0(0 \%)$ & Not significant \\
\hline Closed head injury and concussion & $1(2 \%)$ & $0(0 \%)$ & Not significant \\
\hline Cerebrospinal fluid leak & $0(0 \%)$ & $1(1 \%)$ & Not significant \\
\hline Delayed extubation & $0(0 \%)$ & $1(1 \%)$ & Not significant \\
\hline Device failure* & $1(2 \%)$ & $2(2 \%)$ & Not significant \\
\hline Difficulty breathing & $0(0 \%)$ & $1(1 \%)$ & Not significant \\
\hline Dysphagia* & $3(5 \%)$ & $11(11 \%)$ & Not significant \\
\hline Hematoma & $0(0 \%)$ & $1(1 \%)$ & Not significant \\
\hline Hypothermia & $0(0 \%)$ & $1(1 \%)$ & Not significant \\
\hline Meningitis & $1(2 \%)$ & $0(0 \%)$ & Not significant \\
\hline Motor evoked potentials dropped & $0(0 \%)$ & $1(1 \%)$ & Not significant \\
\hline Myocardial infarction & $0(0 \%)$ & $2(2 \%)$ & Not significant \\
\hline Neurovascular injury & $0(0 \%)$ & $1(1 \%)$ & Not significant \\
\hline Nonunion* & $13 \dagger(22 \%)$ & $5(5 \%)$ & 0.0033 \\
\hline Placement of pacemaker & $0(0 \%)$ & $1(1 \%)$ & Not significant \\
\hline Pneumonia* & $4(7 \%)$ & $5(5 \%)$ & Not significant \\
\hline Posterior decompression at T2-Т3 & $0(0 \%)$ & $1(1 \%)$ & Not significant \\
\hline Wound infection* & $0(0 \%)$ & $1(1 \%)$ & Not significant \\
\hline Any complication & $21(36 \%)$ & $30(30 \%)$ & Not significant \\
\hline
\end{tabular}

remaining 127 subjects, 103 had follow-up information available (follow-up rate, $81 \%$ ).

The key baseline demographic and clinical parameters of the study groups are summarized in the Appendix. There were no differences in sex, age, race, marital status, presence of associated injuries, ISS, residential status, or comorbid conditions between the two groups.

Of the 101 subjects treated surgically, twelve $(12 \%)$ were treated with anterior odontoid screw fixation; eighty $(79 \%)$, with segmental posterior C1-C2 screw-rod fixation; seven (7\%), with posterior transarticular screw fixation; one (1\%), with Brooks fusion $^{17}$; and one (1\%), with occipitocervical fusion. Of the fifty-eight subjects treated nonsurgically, five (9\%) had softcollar immobilization, forty-seven (81\%) had hard-collar immobilization, and six (10\%) had halo immobilization.

Thirteen subjects (22\%) in the nonsurgical arm had unsuccessful nonsurgical treatment and had subsequent surgical treatment. Of the thirteen patients with unsuccessful nonsurgical treatment, eight developed nonunion and the other five had further fracture displacement.

Changes in the outcomes measures from baseline to the six-month and twelve-month follow-up evaluations are 
The Journal of Bone \& Joint Surgery $\cdot$ Jbjs.org Volume 95-A - Number 8 - April 17, 2013
Functional and Quality-of-Life Outcomes in Geriatric Patients with Type-II Dens Fracture summarized in Table I. On average, all outcome parameters declined significantly compared with the baseline status as demonstrated by significant TIME factors for all. The NDI outcomes in the surgical group were significantly better than those in the nonsurgical group (TIME*ARM interaction, $\mathrm{p}=$ 0.0022). At twelve months after treatment, the NDI increased (worsened) 14.7 points in the nonsurgical cohort $(\mathrm{p}<0.0001)$ compared with a nonsignificant increase (worsening) of 5.7 points in the surgical group $(\mathrm{p}=0.0555)$. The difference in NDI between the surgical and the nonsurgical cohort favoring the surgical cohort was more pronounced at six months than at twelve months (Table I). The nonsurgically treated group also had poorer outcomes in the SF-36v2 dimension Bodily Pain (TIME ${ }^{\star}$ ARM interaction, $\mathrm{p}<0.0001$ ). The nonsurgical group experienced a decline of 7.0 points $(\mathrm{p}<0.001)$ while the surgical cohort experienced nonsignificant improvement of 1.4 points $(\mathrm{p}=0.3334)$.

Changes in the outcome measures adjusted for baseline confounders are summarized in Table II. After this adjustment was completed, the results still favored the surgically treated cohort. Both the NDI and the SF-36v2 Bodily Pain outcomes remained significantly better in the surgical group compared with those in the nonsurgical group $(\mathrm{p}=0.0071$ and $\mathrm{p}=0.0014$, respectively).

An overview of complications is shown in Table III. There were eighty-eight complications reported among the 159 subjects. Although there was a tendency toward a higher proportion of subjects with any complication in the nonsurgically treated cohort, this difference was not significant ( $36 \%$ versus $30 \%$ in the surgical group, $\mathrm{p}=0.4805$ ). Common complications in the surgical group were dysphagia (eleven cases $[11 \%]$ compared with three cases $[5 \%]$ in the nonsurgical group), pneumonia (five cases [5\%] compared with four cases $[7 \%]$ in the nonsurgical group), and acute airway compromise (four cases [4\%] compared with one case [2\%] in the nonsurgical group). Nonunion occurred in twelve subjects $(21 \%)$ in the nonsurgical arm compared with five (5\%) in the surgical arm (Fisher exact test, $\mathrm{p}=0.0033$ ). There were three treatment-related deaths, two $(2 \%)$ in the surgical cohort (one resulting from sepsis due to a sacral decubitus and the other from respiratory failure) and one (2\%) in the nonsurgical group (as a result of choking and subsequent cardiopulmonary failure).

\section{Discussion}

This study is among the largest prospective investigations of dens fractures performed to date. We demonstrated that surgical treatment of dens fractures provided a significant benefit relative to outcomes measured with the NDI, a disease-specific functional outcome measure for cervical spine pathology. Furthermore, outcomes in the SF-36 Bodily Pain domain were significantly better in the surgical group compared with the nonsurgical group. In contrast, comparison of other SF-36 scores between the nonsurgical and surgical groups did not demonstrate significant differences; this may suggest that other dimensions of this generic health outcome measure are too coarse, or not rel- evant, to detect the contribution of a dens fracture to an elderly patient's general well-being.

Our study had limitations. Although it was performed in a prospective manner, the patients were not randomized; instead, treatment decisions were made on a clinical case-by-case treatment-preference basis. In this sense, our study could be subject to selection bias; it is possible that surgeons elected to operate on healthier patients and to leave nonsurgical treatment for sicker individuals or that less healthy patients refused surgical intervention. To mitigate this shortcoming, we adjusted study results using a series of confounding variables, including baseline comorbidity. Surgeon preferences for the type of treatment at many centers were demonstrated by the wide variation in institutional surgical rates. It is possible that selection bias affected our results in a manner that we could not correct through statistical confounder adjustment. Other confounding variables that we did not anticipate and control for, such as differences in post-treatment management and rehabilitation, could explain findings of our study. A second limitation of our study is the relatively short follow-up period of one year. Because of the advanced age of the cohort and previous studies that demonstrated substantial twelve-month mortality rates ${ }^{5,7,18}$ after dens fracture, one year was thought to represent a clinically important time horizon for the reporting of our results.

Measurement of functional outcomes with the NDI and SF-36v2, which are both validated instruments, showed that elderly patients with a dens fracture do not regain their preinjury level of function; in fact, the patients had significantly worse scores for almost all outcome measures used in our study. This finding is in contrast to that of Platzer et al. ${ }^{19}$, who described no decline in the functional results in a cohort of elderly patients treated with either C1-C2 posterior fusion or odontoid screw fixation. Platzer et al., however, reported results using the Smiley-Webster scale, a four-part classification system described initially for lumbar disc herniation, which may not be sufficiently sensitive to demonstrate more subtle changes in function and has never been validated. We found that the NDI score worsened significantly from baseline in both groups, demonstrating an increase of 14.7 points in the nonsurgical group and an increase of 5.7 points in the surgical group. The change in NDI between the preinjury and one-year follow-up time points in the nonsurgically treated group exceeds the NDI minimum clinically important difference of 7.5 points previously described by Carreon et al. ${ }^{20}$, although no studies have established the minimum clinically important difference specific to a cervical trauma cohort. In contrast, while the NDI at one year was worse compared with baseline in the surgical group, this difference falls short of the minimum clinically important difference, suggesting that it may not be clinically relevant. The difference in the change in NDI between the nonsurgical group and surgical group was 9 . This difference exceeds the minimum clinically important difference and could suggest that the average patient treated surgically would have a clinically relevant improvement in functional outcome at one year compared with a patient treated nonsurgically. 
The Journal of Bone \& Joint Surgery · Jbjs.org Volume 95-A · Number 8 · April 17, 2013
Functional and Quality-of-Life Outcomes in Geriatric Patients with Type-II Dens Fracture
Survival at one year was relatively high in both groups. Overall, our series had a one-year mortality rate of $18 \%: 26 \%$ of the patients treated nonsurgically and $14 \%$ of the patients treated surgically died. This rate is lower than rates in previous clinical series, in which acute in-hospital mortality alone has ranged from $11 \%$ to $35 \% \%^{4,5,7,10-12}$. This difference may be due to the selection of patients in our study. To be enrolled, patients had to be able to provide informed consent and participate in a number of study-related procedures. Nonetheless, our data suggest that most elderly patients with a dens fracture survive the acute postinjury period. Higher survivorship and the relative rarity of devastating neurological injury associated with this injury reinforce the importance of maximizing quality of life and returning patients to their previous level of function. The decision about whether an elderly patient should undergo surgery for a Type-II dens fracture should not be based on age alone; most elderly patients will survive without substantial neurological deficits.

Much of the discussion about treatment of elderly patients with a Type-II dens fracture has centered on comparisons of the complication rates of nonsurgical and surgical treatment. High complication rates have been described in association with halo vests ${ }^{4,7,11}$, cervical orthoses ${ }^{10,11}$, as well as surgical treatment ${ }^{6,12}$, which reflects the fragile nature of this patient population. We found a higher complication rate in patients treated nonsurgically, although this difference was not significant. Despite the fact that this is the largest prospective study of patients with dens fractures to our knowledge, the number was not sufficient for us to detect significant differences in rates of rare events. We did not analyze the effects of types of surgical care and the quality of surgical reduction and fixation in this study but rather considered surgical care as a single entity. In future subgroup analyses, we hope to investigate whether patients treated surgically and nonsurgically have differential outcomes based on type of treatment.

We found that the rate of nonunion after nonsurgical treatment was significantly higher than that after surgical treatment $(21 \%$ compared with $5 \%$; $p=0.0033)$. High nonunion rates after nonsurgical treatment have been previously described ${ }^{5,21-23}$. Lennarson et al. ${ }^{24}$ performed a case-control study that identified age as a significant predictor of nonunion after halo immobilization. This is consistent with the results in a major systematic review ${ }^{25}$, which favored surgical treatment for displaced dens fractures over nonsurgical treatment on the basis of low-level evidence. The clinical relevance of a dens nonunion in elderly patients is not yet clear. Some authors have advocated that a stable fibrous union can serve as a desirable end point ${ }^{26,27}$ because of the paucity of literature describing adverse consequences of fibrous union in this population and the limited activity and lifespan of elderly patients with a dens fracture. In our experience, however, nonunion was frequently not well tolerated; thirteen $(22 \%)$ of the fifty-eight patients treated nonsurgically crossed over to the surgical group because of symptomatic nonunion or late fracture displacement, suggesting that nonunion is not a desirable end point. Performing primary fusion in patients fit enough for surgery not only may yield superior results but also avoids the need for surgical intervention on a delayed basis and the morbidity and mortality associated with prolonged management.

In conclusion, our study based on prospective data obtained with validated outcome measures may provide useful guidance for surgeons when they are advising geriatric patients and their families about treatment for Type-II dens fractures. Patients who sustain a Type-II dens fracture will have persistent postinjury disability related to their injury. At one year after injury, NDI scores were worse regardless of treatment type, although this decline exceeded the minimum clinically important difference only in the nonsurgical group. Patients and their families should be counseled that treatment might not restore the average patient to his or her preinjury level of function. The relatively lower mortality and improved functional outcome in geriatric patients treated with surgery compared with those who had nonsurgical management favor surgical management. We recommend that elderly patients with a Type-II dens fracture who are healthy enough for general anesthesia be considered for surgical stabilization to improve functional outcome and increase fracture union and the fusion rate.

\section{Appendix}

eA A table showing patient demographics by type of treatment is available with the online version of this article as a data supplement at jbjs.org.

Alexander R. Vaccaro, MD, $\mathrm{PhD}$

Christopher K. Kepler, MD, MBA

Rothman Institute, Thomas Jefferson University, 925 Chestnut Street, 5th Floor, Philadelphia, PA 19107.

E-mail address for A.R. Vaccaro: alexvaccaro3@aol.com

Branko Kopjar, MD, $\mathrm{PhD}$, MS

University of Washington, Box 359455, 4333 Brooklyn Avenue N.E., Room 14-315, Seattle, WA 98195-9455

Jens Chapman, MD

University of Washington, 325 Ninth Avenue, Seattle, WA 98104

Christopher Shaffrey, MD

University of Virginia, P.O. Box 800386,

Charlottesville, VA 22908-0386

Paul Arnold, MD

University of Kansas, 3901 Rainbow Boulevard, Mail Stop 3021, Kansas City, KS 66160

Ziya Gokaslan, MD

Johns Hopkins University, Meyer 7-109, 600 North Wolfe Street, Baltimore, MD 21287 
The Journal of Bone \& Joint Surgery $\cdot$ JbjS. org Volume 95-A • Number 8 · April 17, 2013

Darrel Brodke, MD

University of Utah, 590 Wakara Way, Salt Lake City, UT 84108

John France, MD

West Virginia University,

One Medical Center Drive,

Morgantown, WV 26506

Mark Dekutoski, MD

Mayo Clinic, 200 First Avenue S.W., Rochester, MN 55902

Rick Sasso, MD

Indiana Spine Group, 8402 Harcourt Road,

Suite 400, Indianapolis, IN 46260
Functional and Quality-of-Life Outcomes in Geriatric Patients with Type-II Dens Fracture

S. Tim Yoon, MD

Emory University, 59 Executive Park South, Atlanta, GA 30329

Christopher Bono, MD

Brigham and Women's Hospital,

75 Francis Street, Boston, MA 02115

James Harrop, MD

Thomas Jefferson University, 909 Walnut Street, 2nd Floor, Philadelphia, PA 19107

Michael G. Fehlings, MD, PhD

Toronto Western Hospital, West Wing, 4th Floor,

Room 4WW449, 399 Bathurst Street,

Toronto, ON M5T 2S8, Canada

\section{References}

1. Ryan MD, Henderson JJ. The epidemiology of fractures and fracture-dislocations of the cervical spine. Injury. 1992;23(1):38-40.

2. Lieberman IH, Webb JK. Cervical spine injuries in the elderly. J Bone Joint Surg Br. 1994 Nov;76(6):877-81.

3. Bednar DA, Parikh J, Hummel J. Management of type II odontoid process fractures in geriatric patients; a prospective study of sequential cohorts with attention to survivorship. J Spinal Disord. 1995 Apr;8(2):166-9.

4. Müller EJ, Wick M, Russe $O$, Muhr G. Management of odontoid fractures in the elderly. Eur Spine J. 1999;8(5):360-5.

5. Frangen TM, Zilkens C, Muhr G, Schinkel C. Odontoid fractures in the elderly: dorsal C1/C2 fusion is superior to halo-vest immobilization. J Trauma. 2007 Jul;63(1):83-9.

6. Andersson S, Rodrigues M, Olerud C. Odontoid fractures: high complication rate associated with anterior screw fixation in the elderly. Eur Spine J. 2000 Feb; 9(1):56-9.

7. Kuntz C 4th, Mirza SK, Jarell AD, Chapman JR, Shaffrey CI, Newell DW. Type II odontoid fractures in the elderly: early failure of nonsurgical treatment. Neurosurg Focus. 2000 Jun 15;8(6):e7.

8. Harrop JS, Sharan AD, Przybylski GJ. Epidemiology of spinal cord injury after acute odontoid fractures. Neurosurg Focus. 2000 Jun 15;8(6):e4.

9. Harrop JS, Hart R, Anderson PA. Optimal treatment for odontoid fractures in the elderly. Spine (Phila Pa 1976). 2010 Oct 1;35(21 Suppl):S219-27.

10. Hanigan WC, Powell FC, Elwood PW, Henderson JP. Odontoid fractures in elderly patients. J Neurosurg. 1993 Jan;78(1):32-5.

11. Tashjian RZ, Majercik S, Biffl WL, Palumbo MA, Cioffi WG. Halo-vest immobilization increases early morbidity and mortality in elderly odontoid fractures. J Trauma. 2006 Jan;60(1):199-203.

12. Smith $H E$, Kerr $S M$, Maltenfort $M$, Chaudhry $S$, Norton $R$, Albert TJ, Harrop J, Hilibrand AS, Anderson DG, Kopjar B, Brodke DS, Wang JC, Fehlings MG, Chapman JR, Patel A, Arnold PM, Vaccaro AR. Early complications of surgical versus conservative treatment of isolated type II odontoid fractures in octogenarians: a retrospective cohort study. J Spinal Disord Tech. 2008 Dec;21(8):535-9.

13. Vernon $\mathrm{H}$, Mior $\mathrm{S}$. The Neck Disability Index: a study of reliability and validity. J Manipulative Physiol Ther. 1991 Sep;14(7):409-15.

14. Vernon $\mathrm{H}$. The Neck Disability Index: state-of-the-art, 1991-2008. J Manipulative Physiol Ther. 2008 Sep;31(7):491-502.
15. Ware JE Jr, Sherbourne CD. The MOS 36-item short-form health survey (SF-36). I. Conceptual framework and item selection. Med Care. 1992 Jun;30(6):473-83. 16. Guilfoyle MR, Seeley H, Laing RJ. The Short Form 36 health survey in spine disease_-validation against condition-specific measures. Br J Neurosurg. 2009 Aug;23(4):401-5.

17. Brooks AL, Jenkins EB. Atlanto-axial arthrodesis by the wedge compression method. J Bone Joint Surg Am. 1978 Apr;60(3):279-84.

18. Majercik S, Tashjian RZ, Biffl WL, Harrington DT, Cioffi WG. Halo vest immobilization in the elderly: a death sentence? J Trauma. 2005 Aug;59(2):350-6; discussion 356-8.

19. Platzer $P$, Thalhammer G, Ostermann R, Wieland T, Vécsei V, Gaebler C. Anterior screw fixation of odontoid fractures comparing younger and elderly patients. Spine (Phila Pa 1976). 2007 Jul 15;32(16):1714-20.

20. Carreon LY, Glassman SD, Campbell MJ, Anderson PA. Neck Disability Index, short form-36 physical component summary, and pain scales for neck and arm pain: the minimum clinically important difference and substantial clinical benefit after cervical spine fusion. Spine J. 2010 Jun;10(6):469-74. Epub 2010 Apr 1.

21. Wang GJ, Mabie KN, Whitehill R, Stamp WG. The nonsurgical management of odontoid fractures in adults. Spine (Phila Pa 1976). 1984 Apr;9(3):229-30.

22. Polin RS, Szabo T, Bogaev CA, Replogle RE, Jane JA. Nonoperative management of Types II and III odontoid fractures: the Philadelphia collar versus the halo vest. Neurosurgery. 1996 Mar;38(3):450-6; discussion 456-7.

23. Koivikko MP, Kiuru MJ, Koskinen SK, Myllynen P, Santavirta S, Kivisaari L. Factors associated with nonunion in conservatively-treated type-ll fractures of the odontoid process. J Bone Joint Surg Br. 2004 Nov;86(8):1146-51.

24. Lennarson PJ, Mostafavi $\mathrm{H}$, Traynelis VC, Walters BC. Management of type II dens fractures: a case-control study. Spine (Phila Pa 1976). 2000 May 15;25(10): 1234-7.

25. Patel AA, Lindsey R, Bessey JT, Chapman J, Rampersaud R; Spine Trauma Study Group. Surgical treatment of unstable type II odontoid fractures in skeletally mature individuals. Spine (Phila Pa 1976). 2010 Oct 1;35(21 Suppl):S209-18.

26. Stoney J, O'Brien J, Wilde P. Treatment of type-two odontoid fractures in halothoracic vests. J Bone Joint Surg Br. 1998 May;80(3):452-5.

27. Hart R, Saterbak A, Rapp T, Clark $C$. Nonoperative management of dens fracture nonunion in elderly patients without myelopathy. Spine (Phila Pa 1976). 2000 Jun 1;25(11):1339-43. 